\title{
An optimization model based dynamic EVM and its visualization technique for complex projects
}

\author{
Yun TIAN Ying-ying Yuan Jin-long Cao Yi-yong Xiao \\ School of Reliability and System Engineering,BeihangUniversity,Beijing, 100191,China \\ control. In this paper, we presented a dy- \\ is not start. If $0<f_{i t}<1$, item $i$ is in pro- \\ gress. \\ $s_{i t}$ start time of item $i$ at time $t$ \\ $e_{i t}$ finish time of item $i$ at time $t$ \\ $h_{i t}$ actual period of item $i$ at time $t$ (if $t=0$, \\ $h_{i 0}=h^{*}{ }_{i}$; if $t \geq e_{i t}, h_{i t}$ is the actual period; \\ if $0 \leq t \leq e_{i t}, h_{i t}$ is the EVM forcast \\ period) \\ $c_{i t}$ actual cost of item $i$ at time $t$ (if $t=0$, \\ $c_{i 0}=c_{i}^{*}$; if $t \geq e_{i t}, c_{i t}$ is the actual cost; if \\ $0 \leq t \leq e_{i t}, c_{i t}$ is the EVM forcast cost) \\ $n$ quantity of all items
}

\begin{abstract}
The supervision of Complex equipment development (CED) projects is facing a lot of challenges in scheduling and cost namic earned value management (DEVM) model based on mathematical programming for the real-time forecast of schedule/cost of CED projects. A similarity matrix of the items was introduced into the model to improve the accuracy of the forecasts. Moreover, we proposed a practical technique called Four-quadrant Diagram of Schedule-Cost to dynamically visualize the performances of a CED project, and a new index named Earned Value Divergence to evaluate to what degree the project is controlled. Finally, a case study was provided to illustrate the performance of this method.
\end{abstract}

Keywords: dynamic EVM forecast; similarity matrix; Four-quadrant Diagram of Schedule-Cost; Earned Value Divergence

\section{NOTATION}

$w_{i}$ ID of item $i$

$\Gamma_{i}$ son items of item $i$. If $\Gamma_{i}=\varnothing$, item $i$ is bottom lever item. If $\Gamma_{i}^{-}=\varnothing$, item $i$ is top level item

$h_{i}^{*}$ planned period of item $i$

$c^{*}{ }_{i}$ planned cost of item $i$

$f_{i t}$ completion rate of item $i$ at time $t$. If $f_{i t}=1$, item $i$ is finished. If $f_{i t}=0$, item $i$

\section{INTRODUCTION}

The complexity of equipment development is increasing as time goes by, and this complexity leads to overspend and delay of many equipment development projects. Take F-22A Program as an example. The report submitted in May 2012 by United States Government Accountability Office (GAO) showed that the estimated total cost of the program more than doubled since the program started. The schedule for delivering full capabilities will also be delayed from 2010 to 2017. New techniques of visualization and oversight of complex program is required ${ }^{[1]}$.

Quite a lot of researches have been done of complex projects. However, by now, it has not yielded any perfect theoretical system [2]. A Dynamic Earned Value Management is proposed in this paper to deal with the visibility and accuracy of complex projects. 
Earned Value Management is an effective management technique that provides an accurate status of a project by considering both project plan and performance. It was first sponsored at 1960s by US Department of Defense and particularly for large-scale projects ${ }^{[3]}$. As its popularity in private sector, the theory increasingly consummates. A study showed that $82 \%$ managers use EVM when managing their projects ${ }^{[4]}$.

Vandevoorde $\mathrm{S}$ et $a l^{[5]}$ proved that forecasting duration with earned value metrics provides reliable warning signals at higher WBS levels. As is shown in the comparison among the three main duration forecasting metrics, which are the planned value method ${ }^{[6]}$, the earned duration method ${ }^{[7]}$ and the earned schedule method ${ }^{[8]}$, the third one was the only method which showed satisfying and reliable results during the whole project duration. Lipke $\mathrm{W}$ applied statistical measurable to $\mathrm{EVM}^{[9]}$, and gave the project cost and schedule a predicted upper and lower bounds which showed good performance regardless of confidence level chosen $^{[10]}$. Naeni L M et al ${ }^{[11]}$ put forward a fuzzy approach to evaluate the progress of a project where uncertainty arises. DING Bao-feng et $a l^{[12]}$ introduced the conception of weight earned value to resolve vital path problem of schedule measurement methods based on analyzing the property of total time difference. The conception provides project measurement with a more accurate basis. Pajares $\mathrm{J}$ et al $^{[13]}$ proposed two monitoring indexes of the Cost Control Index and the Schedule Control Index which combined EVM and Project Risk Management to analyze the possible risks. Taking the disadvantages and limitations of traditional EVM into consideration, CHANG Qing et $a l^{[14]}$ put forward a conception of second- level earned value method combined with project network diagram, which corrects the EVM forecasting de- viation. However, no theory has focused on the forecast of the unstarted items since now.

As for the visualization of EVM, Chou J S et al ${ }^{[15]}$ integrated earned value analyze and database management system (DBMS). This realizes a Web-based visualized EVM for assessing project performance.

As all the items of a project are not the same, using the total SPI/CPI to forecast the project will lead to some mistakes. A way to forecast the unstarted items is required. It's also important to get an easily used graphical tool for earned value management.

This paper is organized as follows. In section 2, we introduce the mathematical programming model for the total period/cost of complex projects. In section 3, we apply dynamic EVM (DEVM) method with a new forecasting way for the unstarted items by considering the relationship between items to the model. In section 4 , a simple visualize diagram is put forward to provide a graphical project performance for project managers. In section 5 , a case study is carried out to prove the method we proposed. And in section 6 we conclude the paper.

\section{Mathematical programming model for complex projects}

To get the total period of complex projects, a mathematical programming model is formed in this section.

We use a combination of four elements named $H$ to explain a project:

$$
H=<W(t), U, V, R>_{t}
$$

In which $W(t)$ represents project's WBS (Work Breakdown Structure) which is the foundation for project management. WBS of complex projects can be quite complicated.

$U 、 V 、 R$ represent three typical constraint relations between work items, 
which are precedence, exclusion, father and son.

By using the introduced notation, $H$ is explained as follows:

a) Items' condition differs from time to time. Thus WBS is a combination of the following elements with a time variable $i$ :

$W(t)=\left\{\left(w_{i}, \Gamma_{i}, h_{i}^{*}, c_{i}^{*}, f_{i t}, h_{i t}, c_{i t}, s_{i t}, e_{i t}\right)\right\}_{t}, i=1,2, \cdots \cdots, n$

b) $U$ is for precedence constraint. To every $u_{k}=(i, j)_{k} \in \quad U=\left\{u_{k}|k=1,2, \ldots| U \mid,\right\}$, item $j$ shouldn't start before item $i$ ends. $|U|$ is the amount of elements in $U$.

c) $V$ is for exclusion constraint. To every $v_{k}=(i, j)_{k} \in V=\left\{v_{k}|k=1,2, \ldots| V \mid,\right\}$, item $i$ and item $j$ shouldn't be carried out at the same time. $|V|$ is the amount of elements in $V$.

d) $R$ is for father and son constraint. To every $r_{k}=(i, j)_{k} \in R=\left\{r_{k}|k=1,2, \ldots| R \mid,\right\}$, item $i$ is the father of item $j$, which means item $j$ is covered by item $i .|R|$ is the amount of elements in $R$.

Based on the descriptions above, the mathematical programming model for the shortest expected period is described as follows:

$$
\operatorname{Min} . T(t, S)=\operatorname{Max}\left\{e_{i t} \mid i=1,2,3, \ldots, n\right\}
$$

S. t.:

$$
\begin{aligned}
& S=\left\{s_{i t}\right\} \text { 且 } s_{i t} \in[0, \infty), \forall i=1,2,3, \ldots, n(2) \\
& e_{i t} \leq s_{j t}, \forall(i, j)_{k}=u_{k} \in U \\
& e_{i t} \leq s_{j t} \text { Or } s_{i t} \geq e_{j t}, \forall(i, j)_{k}=v_{k} \in V \text { (4) } \\
& s_{i t} \leq s_{j t} \& e_{i t} \geq e_{j t}, \forall(i, j)_{k}=r_{k} \in R \\
& e_{i t}=s_{i t}+h_{i t}
\end{aligned}
$$

The objective function (1) aims at the minimization of the forecast total project period. Constraint (2) ensures that the start time $s_{i t}$ is a nonnegative integer. Constraints (3)-(5) require that when items are under constraint of $U$ or $V$ or $R$, the constraint must be satisfied. Equation (6) expresses the relationship among the finish time, start time and construction period of item $i$.

The model can get a solution with LINGO or CPLEX.

\section{Dynamic Earned Value Manage- ment}

To get the start time $\left(s_{i t}\right)$ and finish time $\left(e_{i t}\right)$ and cost $\left(c_{i t}\right)$ of every item, we apply earned value management (EVM) to the mathematical programming model to get the forecast of its period (hit) and cost $\left(c_{i t}\right)$. This achieves the dynamic of earned value management (DEVM).

EVM is a useful technique for performance evaluating and information feedback by providing cost and schedule forecast. There are three fundamental parameters in EVM: planned value (PV) is the budgeted costs of work scheduled, actual value (AV) is the actual cost for work performed, and earned value (EV) is the budgeted cost of work performed.

Based on the above three parameters, four indexes are used to evaluate the performance of a project, which are cost variance $(\mathrm{CV})$, schedule variance $(\mathrm{SV})$, cost performance index (CPI), schedule performance index (SPI). Here are the formulas:

$$
\begin{aligned}
& C V=E V-A V, S V=E V-P V, \\
& C P I=E V / A V, S P I=E V / P V .
\end{aligned}
$$

We symbol $c^{\prime}{ }_{i}$ and $h^{\prime}{ }_{i}$ as the actual cost and period of item $i$ at monitoring time $t$. By using notations mentioned above, EVM indexes can be expressed as follows:

$$
\begin{aligned}
& P V_{i t}= \begin{cases}c^{*}{ }_{i} & t-s_{i t} \geq h^{*}{ }_{i} \\
c^{*}{ }_{i} \times \frac{t-s_{i t}}{h^{*}{ }_{i}} & t-s_{i t}<h^{*}{ }_{i}\end{cases} \\
& A V_{i t}=c_{i}^{\prime} \\
& E V_{i t}=f_{i t} \times c^{*}{ }_{i} \\
& C V_{i t}=E V_{i t}-A V_{i t}, S V_{i t}=E V_{i t}-P V_{i t}, \\
& C P I_{i t}=E V_{i t} / A V_{i t}, S P I_{i t}=E V_{i t} / P V_{i t} .
\end{aligned}
$$


Thus at monitoring time $t$, we propose an EVM based cost and period expression.

$$
\begin{gathered}
c_{i t}= \begin{cases}c_{i}^{\prime} & f_{i t}=1 \\
c^{*}{ }_{i} / C P I_{i t} & 0<f_{i t}<1 \\
c_{i t}^{\prime} & f_{i t}=0\end{cases} \\
h_{i t}= \begin{cases}h_{i}^{\prime} & f_{i t}=1 \\
h^{*}{ }_{i} / S P I_{i t} & 0<f_{i t}<1 \\
h_{i t}^{\prime} & f_{i t}=0\end{cases}
\end{gathered}
$$

As few researches have been done on the forecast of items that have not yet started, which can't provide the CPI or $S P I$ of themselves, we propose a similarity matrix to solve the problem. Items can have some similarities in the cost structure and the development method. And the similarity can be described with a number between 0 and 1. That's how the unstarted items can learn from the items already started.

Making $\mathrm{Y}=\left\{y_{i j}\right\}$ is the cost structure similarity matrix, and $\mathrm{Z}=\left\{z_{i j}\right\}$ is the development method similarity matrix, which show all similarities between item $i$ and item $j$, we improve the forecast method to do the forecast of those unstarted items:

$$
\begin{aligned}
& c_{i t}^{\prime}=\frac{1}{p+q} \sum_{j=1}^{p+q}\left[c_{i}^{*} \times\left(1-y_{i j}\right)+c^{*}{ }_{i} \times y_{i j} \div C P I_{j t}\right] \\
& h_{i t}^{\prime}=\left\lceil\frac{1}{q} \times \sum_{j=1}^{p+q} l_{j t} \times\left[h_{i}^{*} \times\left(1-z_{i j}\right)+h_{i}^{*} \times z_{i j} \div S P I_{j t}\right]\right\rceil \\
& l_{j t}= \begin{cases}0 & f_{j t}=1 \\
1 & 0<f_{j t}<1\end{cases}
\end{aligned}
$$

In these two formulas, $p$ is the amount of the items which are finished at monitoring time $t . q$ is the amount of the items which are in progress at monitoring time $t . c_{i}{ }_{i}$ and $h^{*}{ }_{i}$ are the planned cost and period of item $i$.

\section{Visualization of DEVM}

Considering we can't get the earned value of unstarted items, and the SPI of items already finished is 1 , here we improve the indexes of variance and call it deviation instead. Therefore cost variance $(C V)$ is changed to cost deviation $(C D)$, and schedule variance $(S V)$ to schedule deviation $(S D)$.

The next formulas are explanations of $C D$ and $S D$.

$$
\begin{gathered}
C D_{i t}= \begin{cases}\frac{C V_{i t}}{c^{*}{ }_{i}} & f_{i t} \neq 0 \\
\frac{c^{*}{ }_{i}-c_{i t}^{\prime}}{c^{*}{ }_{i}} & f_{i t}=0\end{cases} \\
S D_{i t}= \begin{cases}\frac{S V_{i t}}{h^{*}{ }_{i}} & 0<f_{i t}<1 \\
\frac{h_{i}^{*}{ }^{*} h_{i t}{ }^{\prime}}{h^{*}{ }_{i}} & f_{i t}=0 \\
\frac{h_{i}{ }^{*}{ }_{i}{ }_{i}}{h^{*}{ }_{i}} & f_{i t}=1\end{cases}
\end{gathered}
$$

Taking every item's condition as a point, a visualized DEVM Four-quadrant Diagram of Schedule-Cost with CD on the horizontal axis and SD on the vertical one can be used to make it easier for project managers to get the whole picture. The following is an example.

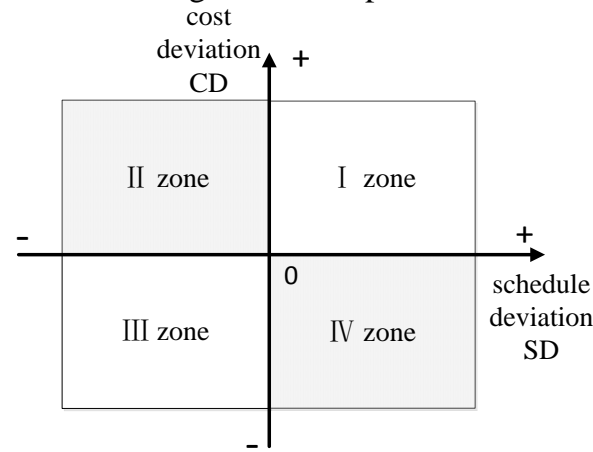

Fig. 1 visualized DEVM Schedule-cost Fourquadrant diagram

Some tricks can be used in this diagram. Let's see some examples.

(1) Distinguish an item's completion state by making the point solid, half solid or hollow. As we introduced, $f_{i t}$ is the completion rate of item $i$ at time $t$. Thus if 
$f_{i t}=1$, the point representing item $i$ is solid. If $f_{i t}=0$, the point is hollow. If $0<f_{i t}<1$, the point is half solid.

(2) Distinguish an item's importance degree by using different size of points. For example, we set three types of points. The largest ones called type A, which represent the quite important items. The smallest ones called type $\mathrm{C}$, which represent the not important items. The middle ones called type $\mathrm{B}$, which represent the rest items.

Project managers may find some other ways to make this diagram more practical for their project. By using the diagram, managers can immediately know how the project is working and how to fix the plan.

Through the Four-quadrant Diagram of Schedule-Cost, we can easily get a plan conformance evaluating way. Here we call it Earned Value Divergence and symbolically represent it by div. This index is a deviation of dispersion. It shows the degree to which the project is controlled. The formula of div is as follows.

$$
d i v=\frac{1}{C(t)} \sum_{i=1}^{n} c_{i t} \sqrt{C D_{i t}{ }^{2}+S D_{i t}{ }^{2}}
$$

The bigger the div is, the greater the mismatch between actual performance and project plan is. Normally, it's not what project managers want. Thus some moves should be taken to make it work well of this project to make the div smaller.

\section{CASE STUDY}

In this section, we set up a case that applies DEVM and its visualization to project management.

The following is the WBS for a project named $X$.

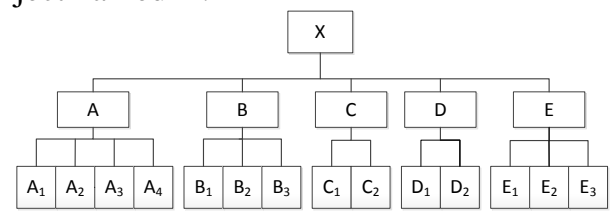

Fig. 3 WBS of project $X$

At monitoring time $t=20^{\text {th }}$ day, we get the general condition of $\mathrm{X}$ as follows.

TABLE I

The executive condition at monitoring time $t$

\begin{tabular}{|c|c|c|c|c|c|c|c|c|}
\hline \multirow{2}{*}{ NO. } & \multirow{2}{*}{$\begin{array}{c}\text { item } \\
w_{i}\end{array}$} & \multirow{2}{*}{$\begin{array}{c}\text { planned } \\
\text { costs } \\
c^{*}{ }^{*}{ }\end{array}$} & \multirow{2}{*}{$\begin{array}{c}\text { planned } \\
\text { period } \\
h^{*}{ }_{i}\end{array}$} & \multicolumn{3}{|c|}{$\begin{array}{c}\text { Monitoring time : } \\
20^{\text {th }} \text { day }\end{array}$} & \multirow{2}{*}{$C P I_{i t}$} & \multirow{2}{*}{$S P I_{i t}$} \\
\hline & & & & $\begin{array}{l}\text { completion } \\
\text { rate } f_{i t}\end{array}$ & $\begin{array}{l}\text { actule } \\
\text { costs }\end{array}$ & $\begin{array}{l}\text { actule } \\
\text { period }\end{array}$ & & \\
\hline 1 & $\mathrm{X}$ & 6500 & 66 & 0.29 & 1900 & - & 0.992105263 & 0.957 \\
\hline 2 & A & 9339 & 27 & 0.65 & 9500 & - & 0.638984211 & 0.8775 \\
\hline 3 & B & 950 & 14 & 1 & 1123 & 19 & 0.845948353 & 1 \\
\hline 4 & $\mathrm{C}$ & 566 & 8 & 1 & 700 & 7 & 0.808571429 & 1 \\
\hline 5 & D & 8452 & 39 & 0 & - & - & - & - \\
\hline 6 & E & 1250 & 24 & 0.2 & 260 & - & 0.961538462 & 0.96 \\
\hline 7 & A1 & 68 & 1 & 1 & 70 & 1 & 0.971429 & 1 \\
\hline 8 & A2 & 8365 & 7 & 1 & 9753 & 8 & 0.857685 & 1 \\
\hline 9 & A3 & 9848 & 4 & 1 & 9950 & 4 & 0.989749 & 1 \\
\hline 10 & A4 & 291 & 15 & 0.47 & 150 & - & 1.94 & 0.88125 \\
\hline 11 & B1 & 1284 & 7 & 1 & 1265 & 6 & 1.01502 & 1 \\
\hline 12 & B2 & 640 & 3 & 1 & 760 & 4 & 0.842105 & 1 \\
\hline 13 & B3 & 1455 & 7 & 1 & 2044 & 9 & 0.71184 & 1 \\
\hline 14 & $\mathrm{C} 1$ & 767 & 2 & 1 & 772 & 2 & 0.993523 & 1 \\
\hline 15 & $\mathrm{C} 2$ & 62 & 6 & 1 & 60 & 5 & 1.033333 & 1 \\
\hline 16 & D1 & 4120 & 9 & 0 & - & - & - & - \\
\hline 17 & D2 & 29602 & 30 & 0 & - & - & - & - \\
\hline 18 & E1 & 2086 & 7 & 0.85 & 1800 & - & 1.158889 & 1.19 \\
\hline 19 & E2 & 1180 & 16 & 0 & - & - & - & - \\
\hline 20 & E3 & 343 & 1 & 0 & - & - & - & - \\
\hline
\end{tabular}


To make it easier for calculating, we suppose the similarity between items are all 0.2. And by using the forecast formula mentioned above, we can get a forecast result as follows.

TABLE II

The forecast results of Project X's items

\begin{tabular}{|c|c|c|c|c|c|c|c|}
\hline $\begin{array}{c}\text { NO. } \\
i\end{array}$ & $\begin{array}{l}\text { ite } \\
\mathrm{m} \\
w_{i}\end{array}$ & $\begin{array}{c}\text { planned } \\
\text { costs } \\
c^{*}{ }_{i}\end{array}$ & $\begin{array}{c}\text { planned } \\
\text { period } \\
h^{*}{ }_{i}\end{array}$ & $\begin{array}{c}\text { actule/ fore- } \\
\text { cast costs } \\
c^{\prime}{ }_{i j}^{\prime} \mathcal{c}^{\prime}{ }_{i t}\end{array}$ & $\begin{array}{c}\text { actule/ fore- } \\
\text { cast period } \\
h^{\prime}{ }_{i}, h^{\prime}{ }_{i t}\end{array}$ & $\mathrm{CD}_{\mathrm{it}}$ & $\mathrm{SD}_{\mathrm{it}}$ \\
\hline 1 & $\mathrm{X}$ & 6500 & 66 & 6551.724138 & 70 & 0.007958 & 0.045455 \\
\hline 2 & A & 9339 & 27 & 14615.38462 & 31 & 0.564984 & 0.148148 \\
\hline 3 & B & 950 & 14 & 1123 & 19 & 0.182105 & 0.357143 \\
\hline 4 & $\mathrm{C}$ & 566 & 8 & 700 & 7 & 0.236749 & -0.125 \\
\hline 5 & D & 8452 & 39 & 8884.674056 & 39 & 0.229336 & 0.025641 \\
\hline 6 & E & 1250 & 24 & 1300 & 23 & 0.04 & 0.041667 \\
\hline 7 & A1 & 68 & 1 & 70 & 1 & 0.029412 & 0 \\
\hline 8 & A2 & 8365 & 7 & 9753 & 8 & 0.165929 & 0.142857 \\
\hline 9 & A3 & 9848 & 4 & 9950 & 4 & 0.010357 & 0 \\
\hline 10 & A4 & 291 & 15 & 319.1489362 & 18 & 0.096732 & 0.2 \\
\hline 11 & B1 & 1284 & 7 & 1265 & 6 & -0.0148 & -0.14286 \\
\hline 12 & B2 & 640 & 3 & 760 & 4 & 0.1875 & 0.333333 \\
\hline 13 & B3 & 1455 & 7 & 2044 & 9 & 0.404811 & 0.285714 \\
\hline 14 & $\mathrm{C} 1$ & 767 & 2 & 772 & 2 & 0.006519 & 0 \\
\hline 15 & $\mathrm{C} 2$ & 62 & 6 & 60 & 5 & -0.03226 & -0.16667 \\
\hline 16 & D1 & 4120 & 9 & 4191.636574 & 9 & 0.067072 & 0 \\
\hline 17 & D2 & 29602 & 30 & 30116.70531 & 30 & 0.031706 & 0 \\
\hline 18 & E1 & 2086 & 7 & 2117.647059 & 6 & 0.015171 & -0.14286 \\
\hline 19 & E2 & 1180 & 16 & 1200.517271 & 16 & 0.065555 & 0.0625 \\
\hline 20 & E3 & 343 & 1 & 348.9639187 & 1 & 0.087047 & 1 \\
\hline
\end{tabular}

Through the mathematical programming model, the total period is $T(t)=70$.

From TABLE II and some rules, we can draw a visualized DEVM Fourquadrant Diagram of Schedule-Cost as follows.

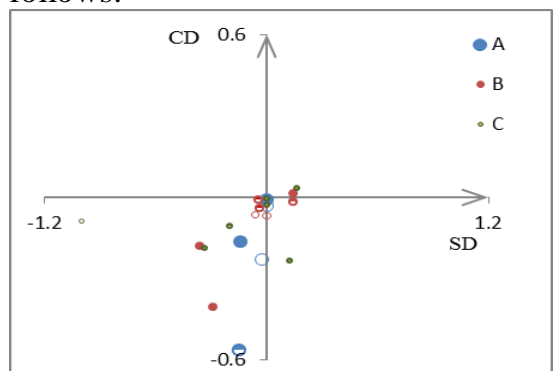

Fig. 4 The visualized DEVM Fourquadrant Diagram of Schedule-Cost of Project $\mathrm{X}$ at monitoring time $\mathrm{t}$

The earned value divergence is 0.176964 .

\section{CONCLUSION}

This paper formed a mathematical programming model for the total period and cost of complex projects. To get some important elements, we apply EVM to it, which realizes the dynamic of earned value management (DEVM). We proposed a similarity matrix for the forecast of unstarted items. This matrix uses the similarity between items. Thus the forecast is based on the reality by the monitoring time which makes the result more realistic. For the visualization of DEVM, we propose a tool called visualized DEVM Four-quadrant Diagram of Schedule-Cost. The diagram provides a graphical performance of the project for project managers. At the same time, we propose a plan conformance evaluating way called Earned Value Divergence to 
evaluate to what degree the project is controlled and analyzed its trend.

\section{References}

[1] United States Government Accountability Office. F-22A Modernization Program Faces Cost, Technical, and Sustainment Risks[R], GAO-12-447. Washington, D.C., May, 2012.

[2] Feng Jinquan. Project Management Organization Planning of the Owner for Large Complex Engineering[J]. Construction Economy, 2011, 3: 35 39. (in Chinese)

[3] Xiong Qinqin. Research on Improvement of the Theory and Methods of Project Earned Value Management[D]. Tianjin:Nankai University, 2010:1-8.

[4] Kim E, Wells Jr W G, Duffey M R. A model for effective implementation of Earned Value Management methodology[J]. International Journal of Project Management, 2003, 21(5): 375 382.

[5] Vandevoorde S, Vanhoucke M. A comparison of different project duration forecasting methods using earned value metrics[J]. International Journal of Project Management, 2006 (24): 289-302.

[6] Anbari F T. Earned value method and extensions[J]. Project Management Journal, 2003, 34(4): 12-23.

[7] Jacob D S, Kane M. Forecasting schedule completion using earned value metrics revisited[J]. The Measurable News, 2004 (3): 11-17.

[8] Lipke W. Schedule is different[J]. The Measurable News, 2003(3): 1015.

[9] Lipke W. Statistical Measurable Applied to EVM - the Next Frontier[J]. Mesa News, 2006: 18-26.
[10] Lipke W, Zwikael O, Henderson K. Prediction of project outcome: The application of statistical methods to earned value management and earned schedule performance indexes $[\mathrm{J}]$. International Journal of Project Management, 2009, 27: 400-407.

[11] Naeni L M, Shadrokh S, Salehipour A. A fuzzy approach for the earned value management[J]. International Journal of Project Management, 2011, 29(6): 764-772.

[12] Ding Baofeng, Zhang Hongguo. The Improvement of Earned Value Analysis in Schedule Measurement Method[J]. Information Technology, 2006 (2): 14-16.

[13] Pajares J, López-Paredes A. An extension of the EVM analysis for project monitoring: The Cost Control Index and the Schedule Control In$\operatorname{dex}[\mathrm{J}]$. International Journal of Project Management, 2011, 29(5): 615621.

[14] Chang Qing, Ji Gedi, Li Changqing. The Research to Second-level Earned Value Method For Improve Performance Measurement of Engineering Project[J]. Chinese Journal of Management Science, 2003, 14(2): 65-70.

[15] Chou J S, Chen H M, Hou C C, Lin $\mathrm{C}$ W. Visualized EVM system for assessing project performance[J]. Automation in Construction, 2010, 19(5): 596-607. 